\title{
Next Wave of COVID-19: Lessons for India from Indonesia, Israel, and Iceland
}

\author{
Purvish M. Parikh ${ }^{1}$ Sachin Hingmire ${ }^{2} \quad$ Nikhil Ghadiyalpatil ${ }^{3}$ \\ ${ }^{1}$ Department of Medical Oncology, Mumbai Oncocare Centers, \\ Thane, Maharashtra, India \\ 2Deenanath Mangeshkar Hospital and Research Centre, Pune, India \\ 3 Yashoda Hospital, Secunderabad, India
}

\section{South Asian J Cancer 2021;00:1-3.}

The coronavirus disease 2019 (COVID-19) pandemic is far from over. While some countries like New Zealand continue to refuse outsiders (including from its neighbor Australia), others are opening their borders with the decision that a symbiotic existence is inevitable (e.g., Singapore). So, what is the real story regarding the short-term future with the ongoing pandemic? World data shows a third peak, and globally the number of new cases has gone up from $2,80,788$ (on June 26 , 2021 ) to 4,66,605 (July 26, 2021). But the distribution of the cases has taken a unique turn. USA has once more taken over as the country with the largest number of new cases $(59,320)$, the hotbed of new cases is now Indonesia with 45,203 new cases (as compared with India's 42,928), and there are 10 other countries with more than 10,000 daily new cases (Thailand, Spain, Iran, France, Italy, Brazil, Russia, UK, Turkey, Argentina).

1. Indonesia as the new epicenter of the CoVID-19 pandemic: With cases growing at $120 \%$, there is fear all over the country as to how this is happening. The answer is multifactorial. Both epidemiologists and officials from the government accept that the recent Eid was a superspreader event, with city inhabitants returning to respective native villages for the post-Ramadan holiday celebrations. Extended families came together for "mudik." With 1.5 million Indonesians having gone home in spite of the government-mandated travel ban, this was inevitable. Complacency regarding COVID-19-appropriate behavior in cities also played their role. Compared with July 2020 , visits to restaurants and shopping centers increased by $18.5 \%$ in 2021 . Indonesia also has higher prevalence of variants of concern (25\%) as compared with neighboring Malaysia (19\%) and Thailand (14\%). In addition, the slow pace of the vaccination as well as the doubts regarding efficacy of the Chinese vaccine have added to the burden-several Indonesian healthcare workers who have received Sinovac have been documented to contact COVID-19 and some have even died. Increase in new cases due to the massive superspreader Eid celebration is expected to peak in 6 to 8 weeks. With the Kerala government having given similar relaxation during Eid (action that was severely criticized by the Supreme Court), the state will have to be ready to deal with the consequences of new case resurgence up to September 2021.

DOI https://doi.org/10.1055/s-0041-1735436 ISSN 2278-330X

How to cite this article: Parikh P. M, Hingmire S, Ghadiyalpatil N, Next Wave of COVID-19: Lessons for India from Indonesia, Israel, and Iceland. South Asian J Cancer 2021;10(1):1-2.
Address for correspondence Purvish $\mathrm{M}$. Parikh, MD, DNB, FICP, PhD, ECMO, CPI, MBA, Department of Medical Oncology, Mumbai Oncocare Centers, 1st Floor,

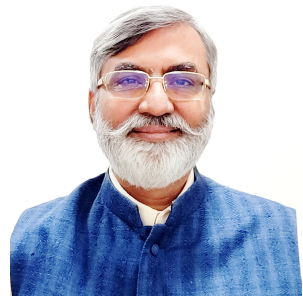

Purvish M. Parikh Blue Nile Building, LBS Road, Thane, Maharashtra, 400601, India (e-mail: Purvish1@gmail.com).

https://asia.nikkei.com/Spotlight/Coronavirus/Why-areIndonesia-s-COVID-cases-surging-Five-things-to-know

2. Vaccination has its limitations: Globally, as of 5:54 pm CEST, July 27, 2021, there have been 194,608,040 confirmed cases of COVID-19, including 4,170,155 deaths, reported to WHO. As of July 25, 2021, a total of 3,696,135,440 vaccine doses have been administered. India has provided to its citizens $11.23 \%$ of all the COVID-19 vaccination doses administered globally (446 million out of global 3,970 million). This is more than USA, UK, France, Italy, Germany, Spain, and Brazil. Yet, social media is full of criticism about Indian initiative. They mention reference to $58.9 \%$ of Israel's population being vaccinated, which actually amounts to a miniscule 11.1 million doses or less than $2.5 \%$ of the number of vaccinations given by India.

On the other hand, we have to understand the limitations of vaccines as well. Not just the quality of the vaccine (ref Sinovac above) but also its efficacy. This is particularly true when we have emerging genetic mutations of concern within the virus. Take the case of Israel. In the last few weeks, their daily new cases have gone up from 208 (on 25 June) to as many as 4,435 (on August 5). No wonder Israel has announced a "booster" to their COVID-19 policy; additional booster dose for their immunocompromised citizens (emulating France). Their decisions are based on two presumptions-immunocompromised people might have a less than optimal immune response to the standard vaccine schedule and that vaccinating this vulnerable population would potentially prevent the emergence of new mutations/variants of concern.

https://www.timesofisrael.com/experts-covid-boostersfor-at-risk-groups-may-help-avert-new-variants/

When Israel with $58.9 \%$ of the population being vaccinated is taking additional precautions, we know that relying upon vaccination alone is not going to be enough.

\section{Vaccination for children-Lessons from the Icelandic experience}

Iceland has also managed to prevent outbreaks while keeping its borders open, welcoming tourists from 45 countries (mainly European countries, USA, and Canada) since mid-June. HoW?

\section{(c) 2021. MedIntel Services Pvt Ltd.}

This is an open access article published by Thieme under the terms of the Creative Commons Attribution-NonDerivative-NonCommercial-License, permitting copying and reproduction so long as the original work is given appropriate credit. Contents may not be used for commercial purposes, or adapted, remixed, transformed or built upon. (https://creativecommons.org/licenses/by-nc-nd/4.0/).

Thieme Medical and Scientific Publishers Private Ltd A-12, Second Floor, Sector -2, NOIDA -201301, India 
Unlike New Zealand, which closed its borders, elimination was never supported in Iceland for fears that the country would go bankrupt without tourism.

They conducted a study among people at high risk of COVID-19 infection (symptomatic, recent travel to high-risk countries, or contact with infected individuals). They also did a population screening involving 2,283 persons. COVID-19 viral sequencing was done from 643 samples. This means $6 \%$ of their population was screened, $87(0.8 \%)$ in the open-invitation screening, $13(0.6 \%)$ in the random-population screening, and 1,221 of 9,199 persons (13.3\%) who tested positive for infection. Two very interesting trends have emerged.

Children under 10 years of age were less likely to receive a positive result than were persons 10 years of age or older, with percentages of 6.7 and $13.7 \%$, respectively, for targeted testing; in the population screening, no child under 10 years of age had a positive result, as compared with $0.8 \%$ of those 10 years of age or older. Fewer females than males received positive results both in targeted testing (11.0 vs. 16.7\%) and in population screening ( 0.6 vs. $0.9 \%$ ).

N Engl J Med 2020; 382:2302-2315. DOI: 10.1056/ NEJMoa2006100. https://www.nejm.org/doi/full/10.1056/ NEJMoa2006100

\section{Spread of Severe Acute Respiratory Syndrome Coronavirus 2 (SARS-CoV-2) in the Icelandic Population}

Daniel F. Gudbjartsson, PhD, Agnar Helgason, PhD, Hakon Jonsson, PhD, Olafur T. Magnusson, PhD, Pall Melsted

http://ctri.nic.in/Clinicaltrials/pmaindet2.php?trialid $=56105 \&$ EncHid $=$ \&userName $=$ covaxin ( 2 to 18 years . CTRI/2021/05/033752-from 24521

\section{Covaxin for Kids: COVID-19 Vaccine Trial Results May Be Out by September, says AlIMS Chief}

In view of a probable third wave of the coronavirus pandemic, vaccination trials on children have been underway in the country. Besides Covaxin, Gujarat-based Zydus Cadila is also testing its anti-COVID-19 shot for children (Written by Joydeep Bose I Edited by Meenakshi Ray, Hindustan Times, New Delhi)

Bharat Biotech's Covaxin COVID-19 vaccine trials for children are currently underway and its results are likely to be out by September, said Dr. Randeep Guleria, the Director of the All India Institute of Medical Sciences (AIIMS) in New Delhi. Last month, the AIIMS director told a Delhi-based news organization that Covaxin shots might be available for children by September.

"The vaccines for children should come out now because trials in India are already there in the vaccines which are available in India, Bharat Biotech trial is in the final phase by September, we will have the data," news agency ANI quoted Dr. Guleria as saying on Friday.

Reports said on Monday that the Hyderabad-based pharmaceutical company will administer its indigenous anti-COVID-19 shot to children in the age group of 2 to 6 as part of its vaccination trials for kids.

In view of a probable third wave of the coronavirus pandemic, vaccination trials on children have been underway in the country. Besides Covaxin, Gujarat-based Zydus Cadila is also testing its anti-COVID-19 shot for children.

Vaccine trials for kids are conducted by dividing them into different categories on the basis of their age, with 175 participants from each age group included. Once every participant has been injected with a second dose, an interim report is expected by the end of August. On the basis of this interim trial report, a decision will be taken if the vaccine is safe to be used on children.

CTRI/2021/03/032051 zydus in adults.

\section{Do We Even Need to Vaccinate Children?}

Children rarely develop severe forms of COVID-19, and deaths from the disease are rarer still. Evidence is building that vaccines might block transmission of SARS-CoV-2, so vaccinating children could have beneficial knock-on effects in the wider community. The virus will find ways to survive and spread unless we close off the pathways," says Talaat.

\section{Will Children and Adults Respond Differently to COVID-19 Vaccines?}

Children's immune systems are brimming with cells that haven't seen pathogens, so they tend to produce a strong immune response to vaccines, Early trial results have shown that 12-15-year-olds who received two standard doses of the Pfizer-BioNTech vaccine developed substantially higher levels of virus-blocking antibodies than did 16-25-year-olds in earlier trials. Children's potent immune responses mean that they are more likely than adults to develop a fever after vaccination.

\section{How Will Researchers Know If the Vaccines Are Safe in Young Children?}

"Anything that smears vaccines in general, and makes people question the safety of vaccines in kids, is a step backwards from a public-health standpoint," says Conway.

It is not yet clear how concerns over very rare blood clots potentially linked to the Oxford-AstraZeneca and Johnson \& Johnson vaccines will affect pediatric trials.

Nature 592, 670-671 (2021). doi: https://doi.org/10.1038/ d41586-021-01061-4

Moderna Inc. (Nasdaq: MRNA), a biotechnology company pioneering messenger RNA (mRNA) therapeutics and vaccines, today announced that the first participants have been dosed in the Phase $2 / 3$ study (in USA and Canada), called the KidCOVE study, of mRNA-1273, the company's vaccine candidate against COVID-19, in children aged 6 months to less than 12 years.

https://investors.modernatx.com/news-releases/ news-release-details/moderna-announces-first-participants-dosed-phase-23-study-0

https://clinicaltrials.gov/ct2/show/NCT04796896

(two references for Moderna trial 6 MONTHS upwardswill be recruiting 6975 participants)

Conflict of Interest

None declared. 